\title{
Percepção de Psicólogas Escolares sobre o Processo de Escolha Profissional no
}

\section{Ensino Médio}

\author{
Perception of School Psychologists on the Professional Choice Process in High School \\ Percepción de Psicólogas Escolares sobre el Proceso de Elección Profesional en la Enseñanza Media
}

Recebido: 25/01/2021 | Revisado: 28/01/2021 | Aceito: 01/02/2021 | Publicado: 09/02/2021

Eliane Ribeiro Magalhães de Sousa Fortes de Melo ORCID: https://orcid.org/0000-0002-3496-7901 Universidade CEUMA, Brasil E-mail: elianeek30@gmail.com

Pollianna Galvão Soares de Matos ORCID: https://orcid.org/0000-0001-7579-8852 Universidade CEUMA, Brasil Universidade Federal do Maranhão, Brasil E-mail: polliannagalvao@yahoo.com.br

Daniel Carvalho de Matos ORCID: https://orcid.org/0000-0002-6793-0101 Universidade CEUMA, Brasil

Universidade Federal do Maranhão, Brasil E-mail:dcmatos23@hotmail.com

\begin{abstract}
Resumo
A Psicologia Escolar, como área de intervenção, pesquisa e apoio à formação de estudantes para o campo de trabalho, tem a Orientação Profissional (OP) como um dos seus temas de interesse tradicionais. Nessa direção, este estudo teve como objetivo conhecer a percepção e a atuação de psicólogas escolares sobre o processo de escolha profissional de alunos do Ensino Médio em dois colégios privados de São Luís - MA. Trata-se de uma pesquisa de caráter qualitativo em que os procedimentos envolveram entrevistas com psicólogas e o instrumento utilizado para a construção de informações foi a aplicação de três questionários semiabertos. Os resultados demonstram que as entrevistadas percebem a importância da OP como disciplina integrante da educação formal e a relevância de sua atuação como mediadoras nos processos subjetivos e sociais dos seus discentes. Reitera-se que outros estudos são necessários para ampliar o conhecimento sobre as possíveis contribuições do psicólogo escolar em relação ao papel da escola na trajetória dos sujeitos que no futuro servirão a sociedade por intermédio de suas profissões.
\end{abstract}

Palavras-chave: Adolescência; Escolha e orientação profissional; Psicologia escolar; Aspectos psicossociais.

\begin{abstract}
School Psychology, as an intervention area, research and support for the training of students for a field of work, has the Professional Orientation as one of its traditional themes of interest. With that in mind, this study aims to analyze the perception and performance of four school psychologists on the process of professional choice of high school students in two private schools in São Luís - MA. This is a qualitative research, in which the procedure involved was to interview psychologists and the instrument used to gather the information was the application of three semi-open questionnaires. The results show that the interviewees perceive the importance of Professional Orientation as an integral discipline of formal education and the relevance of their performance as mediators in the subjective and social processes of their students. It is reiterated that other studies are necessary to increase knowledge about the possible contributions of the school psychologist in relation to the role of the school in the trajectory of the subjects that in the future will be serving the society through their professions.

Keywords: Adolescence; Choice and professional orientation; School psychology; Psychosocial aspects.

\section{Resumen}

La Psicología Escolar, como área de intervención, investigación y apoyo a la formación de estudiantes para el campo de trabajo, tiene la Orientación Profesional como uno de sus temas de interés tradicionales. En esta dirección, este estudio tiene como objetivo conocer la percepción y la actuación de cuatro psicólogas escolares sobre el proceso de elección profesional de alumnos de la Enseñanza Media en dos colegios privados de São Luís - MA. Se trata de una investigación de carácter cualitativo en que los procedimientos involucraron entrevistas con psicólogas y el instrumento utilizado para la construcción de informaciones fue la aplicación de tres cuestionarios semiabiertos. Los resultados demuestran que las entrevistadas perciben la importancia de la Orientación Profesional como disciplina integrante de la educación formal y la relevancia de su actuación como mediadoras en los procesos subjetivos y sociales de sus discentes.
\end{abstract}


Se reitera que otros estudios son necesarios para ampliar el conocimiento sobre las posibles contribuciones del psicólogo escolar en relación al papel de la escuela en la trayectoria de los sujetos que en el futuro estarán sirviendo a la sociedad por intermedio de sus profesiones.

Palabras clave: Adolescencia; Selección y orientación profesional; Psicología escolar; Aspectos psicosociales.

\section{Introdução}

A atuação em Psicologia Escolar fundamenta-se em conhecimentos teóricos e metodológicos que possibilitam desenvolver um trabalho mais crítico e dinâmico de mediação do comportamento humano pelas interações sociais no ambiente escolar (Guzzo \& Marinho-Araujo, 2014). Uma das áreas de sua contribuição é a de Orientação Profissional (OP) junto a estudantes do Ensino Médio, podendo ajudá-los a terem consciência de si nesse cenário de segregação social pela carreira e a elevarem o seu nível de criticidade em relação à lógica de mercado atual excludente e competitivo (Facci, 2014). Este trabalho aborda como temática a análise da percepção de psicólogos escolares sobre o processo de escolha profissional no Ensino Médio.

A escolha profissional na educação básica deve situar-se em um contexto mais amplo, de forma reflexiva, considerando os aspectos socioculturais relacionados às indecisões, conflitos e limitações do discente no processo de escolha profissional no qual está inserido, o que deve ser alvo das políticas educacionais no Brasil (Melo-Silva et al., 2019). O psicólogo escolar (PE) pode atuar na escola, não apenas com ênfase nos tipos de profissão e de trabalho, mas com uma prática direcionada aos sentidos e significados que os adolescentes atribuem ao processo de escolha profissional, visto que a sua atuação, quando fundamentada em teorias críticas da Psicologia, dá forma a propostas de intervenção voltadas às relações sociais que ocorrem dentro e fora da escola (Facci, 2014; Martinez, 2010; Oliveira \& Marinho-Araujo, 2010; Santos et al., 2019; Souza, 2014).

Por compreender que o processo de escolha profissional deve ser analisado à luz de fundamentos que situem o estudante no contexto social, político, econômico e cultural ao qual pertence, esta pesquisa fundamentou-se na perspectiva históricocultural da psicologia do desenvolvimento, que tem Vygotsky $(1996,1998,2000)$ como o seu principal representante. As possibilidades de construções subjetivas sobre o presente e o futuro se dão a partir das atividades externas, ou seja, no meio e nas diversas relações sociais vivenciadas na escola, o que o referido autor determina como situação social de aprendizagem (Marinho-Araujo, 2016). Quando se analisa sobre o projeto de vida de uma pessoa, deve-se ficar alerta para as condições nas quais ele é construído. Portanto, é indispensável que se reflita sobre quem é o verdadeiro sujeito desse projeto, se é o estudante ou as múltiplas determinações que o induzem a planos e realizações que, muitas vezes, não são dele. Em outras palavras, devese observar as condições que estão sendo fornecidas para que o adolescente construa e concretize qualquer plano de vida.

Conforme Vygotsky (1996), Facci (2014), Fraiman (2014), Guzzo e Marinho-Araujo (2014) e Lisboa (2017), as escolhas podem ser revistas ao longo da vida, são processos de construção, passíveis de transformações. O jovem, durante esse processo, encontra-se diante de si mesmo, da família, dos pares e da sociedade, ora assumindo um lugar de autonomia, ora de cobranças, imposições e responsabilidades. Salienta-se, então, que muitos adolescentes, ao passar por esse processo complexo acerca da OP, enfrentam algumas dificuldades de escolha sobre a carreira e refletem a necessidade de um apoio psicológico.

Segundo Neiva (2013) e Levenfus (2016), o jovem, nessa fase de escolha profissional vivenciada no contexto escolar, depara-se com influências socioculturais diversas e lida com sentimentos de ansiedade, angústias e medos, uma vez que a decisão sobre a carreira, no presente, acarreta implicações no futuro, sobretudo na trajetória acadêmica no ensino superior. Um recente estudo conduzido por Dias et al. (2019) investigou as principais dificuldades vivenciadas por 423 universitários relacionadas ao início da trajetória acadêmica, por meio de questionários abertos, sendo encontrados e discutidos entre os achados a percepção de que havia dúvidas se o curso frequentado era de fato o desejado pelo estudante nesta transição do ensino e as dificuldades no processo foram relacionadas às diferenças entre o ensino médio e o superior.

Defende-se a importância de haver, nas escolas de Ensino Médio, o profissional de Psicologia Escolar para promover atividades de autoconhecimento, maturidade e conscientização sobre a escolha profissional, o mercado de trabalho e o universo 
subjetivo dos estudantes, nessa etapa de ensino e também em anos anteriores, trabalhando em conjunto com a equipe pedagógica para juntos melhor auxiliarem todos os envolvidos nesse contexto: alunos, professores e familiares. Nessa direção, é importante identificar as práticas dos psicólogos escolares voltadas à OP e avaliar como pensam em relação aos fatores de influência no comportamento do jovem sobre suas escolhas no mundo do trabalho (Ambiel et al., 2019; Facci, 2014; Galvão, 2014; Martinez, 2010; Oliveira \& Marinho-Araujo, 2010; Santos et al., 2019; Souza, 2014).

Esta pesquisa apresenta relevância por buscar compreender se o trabalho que é desenvolvido por psicólogos escolares em OP fundamenta-se em uma perspectiva teórico-metodológica de natureza crítica, voltada para incitar processos de conscientização dos adolescentes de forma lúcida acerca dos aspectos associados a esse processo de transição. A literatura de Psicologia Escolar vem problematizando uma atuação com base em uma tendência individual e clínica no contexto da escola, o que pode estar fundamentada em uma compreensão de homem com ênfase em aspectos inatos e a partir de uma noção individualizante sobre o desenvolvimento profissional, fortalecendo, assim, uma perspectiva da aptidão e prontidão do sujeito para o trabalho, desconsiderando os fatores sociais, políticos, econômicos e culturais do processo. A seguir são apresentadas algumas considerações a respeito da adolescência e o processo de escolha profissional; OP; e atuação do psicólogo escolar, em contexto escolar, por meio de atividades relacionadas a OP.

\subsection{O Adolescente e o Processo de Escolha Profissional}

A adolescência, além de fazer parte de uma construção histórica e de uma produção cultural, também expressa as formas individuais de como cada pessoa vive a passagem da infância para a vida adulta. Nessa direção, Carvalho (2017) relata que são bem visíveis alterações físicas, comportamentais e fisiológicas do indivíduo, desde seu nascimento até a velhice, e ainda destaca o contexto cultural como um elemento chave. Trata-se de uma fase do desenvolvimento humano na qual se tem a clareza quanto ao seu início, identificado pelos eventos da puberdade fisiológica. No entanto, o mesmo não se pode afirmar quanto ao seu fim, pois ser ou não adolescente está relacionado às caracterizações e modificações culturais (Facci, 2014). Observa-se que, muitas vezes, a construção da identidade do sujeito reflete diversas influências do contexto sociocultural que o envolve.

Durante a adolescência, reflexões sobre a profissão são provocadas pelas interações sociais das quais partilham o jovem em diversos contextos, como a escola, e que impactam na vida pessoal e na carreira do indivíduo quando é mobilizado a decidir qual profissão irá seguir (Oliveira \& Marinho-Araujo, 2010). Entretanto, o preparo do adolescente para o desenvolvimento de competências necessários para sua vida em sociedade, e que envolve a sua inserção no mercado de trabalho, ainda é modesto em algumas escolas brasileiras, sobretudo as de natureza pública, uma vez que as condições socioeconômicas são fatores que levam a desdobramento a escolhas profissionais mais desiguais entre adolescentes de diferentes camadas sociais. Nessa direção, concorda-se com Meireles e Guzzo (2020) na afirmação de que a escola pública brasileira é instrumento de governo para a diminuição das desigualdades sociais e ampliação das oportunidades de desenvolvimento humano pela continuidade da educação formal, sendo que o psicólogo escolar deve promover espaços de participação ativa dos estudantes, como sujeitos críticos de si no mundo e protagonistas do seu próprio desenvolvimento na busca de uma profissão.

De acordo com Ambiel et al. (2019), na adolescência principalmente, a participação da família é considerada como um fator relevante para o ato de se escolher uma determinada profissão. Muitas vezes, o adolescente tem pouca consciência crítica sobre os fatores sociais que influenciam a sua escolha profissional, o que pode dificultar a lidarem com essas situações de forma lúcida. De forma similar, Neiva (2013) reforça que a escolha profissional é uma atividade que o sujeito faz dentro de uma realidade social, sofrendo influência das várias instituições que a compõem, como a família, escola, grupo de pares e outras instituições sociais na qual essas microestruturas estão inseridas. O ensino médio é tomado como um ciclo da educação básica durante o qual o adolescente é exigido a tomar uma decisão com relação ao seu futuro profissional. Ele terá que lidar com esse processo de escolha profissional e nem sempre está preparado para realizá-la de forma mais consciente sobre os fatores históricos, 
políticos, sociais e culturais envolvidos (Facci, 2014; Grings \& Jung, 2017).

Vygotsky (1996, p. 200) destaca que a adolescência é “o período das sínteses superiores produzidas pela crise do devenir e da maturação daquelas formações superiores que são o fundamento de toda existência consciente do ser humano". Sem dúvida, nessa etapa, o adolescente passa por um processo de maturidade e autoconhecimento que, obviamente, sofre influência cultura a cultura. No contexto da escola brasileira, os psicólogos escolares têm colaborado, a partir de uma perspectiva crítica e coletiva, com intervenções que colaboram com a ampliação da consciência crítica dos sujeitos inseridos no processo de escolarização, o que envolve a construção de espaços de circulação se significados e sentidos sobre os fenômenos sociais, como o processo de escolha profissional (Meireles \& Guzzo, 2020).

São vários fatores envolvidos no processo da escolha de uma determinada profissão durante o curso de vida do adolescente. Um deles comumente sinalizado pela literatura diz respeito às características socioeconômicas das famílias às quais pertencem (Melo-Silva, Munhoz \& Leal, 2019). Muitos deles contam com uma rede de opções por terem pais com um poder aquisitivo suficiente para arcar com o curso universitário que o filho escolhe. Outros, porém, trabalham desde muito cedo para ajudar no sustento da família. E outros, por terem condições financeiras desfavoráveis, submetem-se a trabalhar no que estiver mais próximo de sua realidade econômica, adiando o grande sonho ou até desistindo dele. Nesse sentido, Grings e Jung (2017) destacam que, no Brasil, a OP atende um jovem que procura conciliar seus anseios pessoais com o mercado de trabalho, direcionando-se a um público de classe média ou alta que retrata a condição de escolha. Todavia, o mesmo não ocorre com alunos pertencentes a famílias de baixa renda, o que provoca a necessidade de ajudar sua família, vindo a trabalhar no que lhe for oferecido.

Facci (2014, p. 129) corrobora com essa visão quando relata que são diversas as transformações "pelas quais os jovens passam na ontogênese, além das modificações em sua vida, é imprescindível considerar a historicidade na compreensão do psiquismo humano e analisar como a nossa sociedade tem tratado do indivíduo nessa fase de desenvolvimento" (p.129). A orientação para o trabalho, nas escolas, é fundamental tanto para os que podem optar quanto para os que são carentes economicamente e não têm condições para escolher, pois ambos precisam desenvolver uma consciência crítica sobre o que influencia a sua atividade profissional.

Conforme Carvalho e Marinho-Araujo (2010), Soares e Krawulski (2010), Oliveira e Neiva (2013) e Lisboa (2017), a OP tem muito a contribuir com a formação dos estudantes do ensino médio, já que a maioria desses estudantes decidem por uma profissão ainda muito jovem em contextos sociais, políticos e econômicos bem distintos, nem sempre de forma madura e consciente, com critérios claros, tendo como base o conhecimento de si próprio e o da realidade profissional. E, assim, quando finalizar o Ensino Médio, uma nova decisão se fará necessária com relação a prosseguir os estudos e/ou ingressar diretamente no mercado de trabalho.

De acordo com Levenfus (2016), o processo dúvida pelo qual o adolescente passa é esperado em uma sociedade capitalista, sendo um indicador importante para o planejamento de ações na escola que possam prover apoio. Nessa direção, intervenções desenvolvidas em OP podem ser conduzidas com psicólogos escolares junto aos demais atores da escola de forma a amenizar processos psicológicos que envolvem insegurança, sofrimento e angústia durante a sua vivência no ensino médio. $\mathrm{O}$ autor destaca que é comum observar adolescentes inseguros frente à possibilidade de fazerem uma escolha errada e, por isso, torna-se importante que o a equipe de orientação profissional trabalhe a ansiedade. Defende-se sobre a importância de que os estudantes tenham momentos de busca, pesquisa e reflexão, de forma ativa e crítica em seu próprio processo, analisando as potencialidades implicadas na tomada de consciência sobre as diversas profissões, de forma a se sentirem mais lúcidos sobre as características envolvidas no seu projeto profissional (Meireles \& Guzzo, 2020). 


\subsection{A Psicologia Escolar e Orientação Profissional (OP)}

Segundo Lehman (2010), Soares e Krawulski (2010) e Lisboa (2017), em um mundo de frequentes transformações, a OP aparece como um processo fundamental em várias etapas da vida onde acontecem rupturas no caminho individual e profissional do indivíduo, devido a mudanças no significado social do trabalho relacionado ao capitalismo globalizado. Observase que, com a chegada da modernidade, ocorreu o inevitável, que é uma constante e crescente necessidade de adquirir conhecimentos especializados, ampliando-se, assim, as exigências relacionadas a um melhor preparo para ingressar no mundo profissional.

Enfatiza-se que se vive, atualmente, em um momento em que cresce o desequilíbrio entre o sistema de formação e o mercado de trabalho. As seleções de emprego estão mais exigentes e o novo lema é o desenvolvimento de um ideal de qualificação perfeita, impecável e, para sobreviver a esse cenário, a OP passa a ter como foco um problema que vai além da escolha de uma profissão, que é a importância do trabalho como modo de inserção social. Os profissionais, que trabalham com OP, vêm buscando diversas estratégias em prol dos estudantes para melhor se adaptarem às transformações constantes deste novo milênio, cercado de uma grande variedade de novas áreas e cursos que surgem a todo instante no meio social (Oliveira \& Marinho-Araujo, 2010).

A escola passou a simbolizar o espaço indicado para essa preparação, como também o lugar no qual se espera oferecer aos estudantes múltiplas oportunidades voltadas ao acesso ao trabalho formal. E tudo isso contribuiu para que haja uma formalização do sistema educativo, buscando uma adequação progressiva entre as formas de vida das crianças, dos adolescentes e dos adultos (Guzzo \& Marinho-Araujo, 2014; Marinho-Araujo, 2016).

Atualmente, os alunos estão cada vez mais sendo cobrados, principalmente, no ensino médio, porque é um período que vai se aproximando de uma decisão em relação ao prosseguimento dos estudos e qual curso/profissão seguir. Carvalho (2017) enfatiza que a vida do ser humano é repleta de interferências, de escolhas em diversos setores. Contudo é especialmente durante esse ciclo que isso se torna crítico, visto que os estudantes são estimulados a focar em escolher uma profissão. É, nessa etapa de ensino, que muitos adolescentes procuram ajuda em intervenções em orientação profissional para a tomada de decisão e a construção do projeto profissional (Oliveira \& Marinho-Araujo, 2010).

Carvalho e Marinho-Araujo (2010) relatam que, no Brasil, a Psicologia Escolar e a OP têm passado por mudanças em suas metodologias e fundamentos, o que possibilita intervenções mais voltadas à promoção do desenvolvimento humano e construção da cidadania. O psicólogo escolar pode desenvolver atividades de OP na escola de maneiras como as seguintes: realização de dinâmicas, oficinas, atividades, palestras e discussão de temas relacionados à escolha da profissão, com a finalidade de levar o adolescente a refletir sobre si mesmo e as opções existentes para o desenvolvimento de carreiras. O jovem deve construir planos e realizar escolhas profissionais criando seus próprios sentidos subjetivos, em um contínuo processo de conscientização, desenvolvendo o seu pensamento crítico voltado a si mesmo e ao contexto social a que pertence (Martinez, 2010; Souza, 2014).

Campos e Noronha (2016) enfatizam que o objetivo da OP é colaborar para que os jovens compreendam melhor essa fase de indecisão, contribuindo para que eles possam chegar a uma escolha mais ajustada, uma vez que as pessoas mais seguras, certamente, estarão mais fortalecidas ao escolherem uma profissão. Concorda-se com as autoras na afirmação de que finalidade da OP é realmente conduzir o jovem à autoavaliação e autoanálise em relação às suas áreas de interesses, aptidões mais específicas, que se apresentam incluídas nas suas possibilidades.

De acordo com Carvalho e Marinho-Araujo (2010), a atuação em Psicologia Escolar envolvida em OP na escola brasileira vem se desenvolvendo predominantemente em três domínios: (a) Psicologia do Trabalho vinculada à Seleção de Pessoal, cujas intervenções centraram-se na modalidade estatística; (b) Psicologia Educacional, centrando-se na passagem de um ciclo educativo a outro; e (c) Aconselhamento, focalizando crises evolutivas no ciclo vital. A partir desses domínios, a OP refere- 
se a uma intervenção processual que tem como objetivo empoderar o indivíduo a realizar escolhas autônomas em busca de sua identidade profissional, provocando o desenvolvimento de competências importantes para seu fortalecimento e segurança na transição entre os níveis de ensino e, mesmo, para sua inserção no mercado de trabalho. Nesse sentido, deve-se fortalecer a importância de se produzir ações na escola em OP não apenas no ensino médio, mas no processo da escolarização da educação básica, buscando o aumento da consciência e autonomia que visem conferir maior segurança durante a passagem para um novo ciclo educativo.

Guzzo e Marinho-Araujo (2014) destacam sobre a participação do psicólogo na equipe escolar, visto que divide tarefas e preocupações com todos os envolvidos na comunidade educativa: professores, diretores e demais membros da comunidade, ajudando em um crescimento positivo para o ambiente escolar, sendo sensível às necessidades referentes ao desenvolvimento das potencialidades e aos problemas socioeconômicos dos alunos. O papel do psicólogo é voltado a auxiliar na conscientização de que a escola não é somente um espaço de desenvolvimento cognitivo, uma vez que as dificuldades dos alunos vão além de fatores individuais e familiares. E, assim, busca a conscientização de toda a equipe pedagógica de que o ambiente escolar é um espaço de construção social, cognitiva, afetiva e histórica (Guzzo \& Marinho-Araujo, 2014). O psicólogo escolar, como um orientador profissional, é um agente de mudanças com capacidade de contribuir para a formação de sujeitos mais ativos e para a otimização do processo educativo, colaborando com ações pedagógicas nas quais venham a ser trabalhados os medos, conflitos e mitos referentes à adolescência e ao processo de escolha profissional dos jovens. Utiliza técnicas de significação e ressignificação das escolhas, de autoconhecimento e de autocrítica sobre o vasto e complexo mundo do trabalho, buscando favorecer a percepção dos estudantes, quanto à sua condição de sujeitos em constante relação dialética, despertando neles o exercício do pensamento crítico e da cidadania.

Diante do que foi exposto sobre OP e possibilidades de contribuições da Psicologia Escolar, esta pesquisa buscou conhecer a percepção de psicólogas escolares acerca do processo de orientação e escolha profissional de estudantes do Ensino Médio de duas escolas privadas brasileiras da cidade de São Luís - MA.

\section{Metodologia}

\subsection{Desenho do Estudo e Objetivos}

Essa pesquisa voltou-se para conhecer as características de atuação em Psicologia Escolar na atividade de Orientação Profissional junto a estudantes do Ensino Médio, uma demanda comumente encontrada entre as demandas de trabalho do psicólogo neste nível da educação básica. Trata-se de um estudo qualitativo em psicologia do desenvolvimento, em que se assume a relação dinâmica entre a realidade social e os participantes, cujo alvo principal é a circulação de falas com significados e os sentidos que são construídos pelos indivíduos em determinado recorte de tempo e espaço social. Este tipo de investigação leva em consideração fenômenos que são desenvolvidos na interação entre indivíduo e o coletivo, fundamentando-se essencialmente por uma abordagem sobre o objeto de análise de maneira processual, interpretativa, dinâmica, histórica e política, considerando como parte do processo de construção das informações a subjetividade tanto dos sujeitos estudados, quanto dos pesquisadores (Flick, 2009).

A partir dessa compreensão, e o delineamento do objetivo central de conhecer a percepção de psicólogas escolares que atuam em orientação profissional referente ao processo de escolha de alunos do ensino médio, esse estudo fundamentou-se na perspectiva histórico-cultural do desenvolvimento humano de Vygotsky (1996, 2000). Para isso, é importante considerar os sujeitos da pesquisa como subjetivamente constituídos em sua própria história, a partir da construção de significados e sentidos (Marinho-Araujo, 2016). Os pressupostos metodológicos desta fundamentação conferem grande importância da linguagem tanto para o desenvolvimento cognitivo como também social do homem, destacando que a linguagem é criada pelo caráter social do indivíduo e que é a partir dessa relação dialética que o ser humano é capaz de abstrair e transmitir a cultura e a história às gerações 
futuras (Marinho-Araujo, 2016).

Desenvolver investigações sob este enfoque significa delinear procedimentos e instrumentos que levem em consideração como esse homem se relaciona com os processos de desenvolvimento ocorridos a partir das transformações de seu entorno. A concepção deste estudo, que está voltado para a área de OP, compreende o sujeito na sua relação com a sociedade de forma dinâmica e dialética, não sendo a favor da dicotomia entre ambos, destacando que o ser humano se constitui na sua relação com o outro social, historicamente constituído nas relações com o mundo, com a cultura (Vygotsky, 1996, 2000).

Para o alcance do objetivo geral do estudo, delinearam-se os seguintes objetivos específicos: conhecer o trabalho desenvolvido pelas psicólogas escolares em OP; identificar o referencial teórico-metodológico de sua atuação; analisar como as psicólogas percebem que as ações desenvolvidas influenciam a escolha profissional dos adolescentes.

\subsection{Participantes e Campo da Pesquisa}

Inicialmente, a pesquisa envolveu com cinco psicólogas escolares de duas escolas privadas de Ensino Médio de São Luís - MA, sendo que uma delas, no desenvolvimento deste trabalho, não respondeu aos questionários. Com isso, os resultados analisados foram de apenas quatro psicólogas.

A primeira instituição visitada era composta por duas unidades localizadas em bairros diferentes de São Luís - MA e conta com Ensino Fundamental I e II e Ensino Médio. A segunda escola possui uma só unidade, contando com Educação Infantil, Ensino Fundamental I e II e Ensino Médio.

\subsection{Aspectos Éticos}

Este trabalho foi submetido à apreciação do Comitê de Ética em Pesquisa (CEP) da Universidade CEUMA, com a finalidade de obedecer à resolução CNS 466/12 em vigor em todo o território nacional. Obteve aprovação pelo mesmo CEP com o parecer: 1.551.085. As participantes receberam um Termo de Consentimento Livre e Esclarecido, o qual garante que todas as informações disponibilizadas serão utilizadas somente neste estudo, sendo totalmente confidenciais. As psicólogas escolares participaram de modo voluntário, e foram comunicadas sobre os pontos referentes à pesquisa como: objetivos, divulgação, sigilo, procedimentos utilizados, isenção de danos, ficando livres para desistirem quando desejassem, sem nenhuma espécie de risco à sua participação.

\subsection{Instrumentos, Procedimentos e Análise das Informações}

Inicialmente, foram realizadas reuniões nas duas escolas para a apresentação e explicação do projeto à equipe escolar: diretora, coordenadora e psicólogas escolares (PE), coleta da assinatura do Termo de Anuência Institucional e dos primeiros dados sobre o trabalho das psicólogas referente à OP. Após essa etapa preliminar, foram enviados questionários eletrônicos por e-mail das psicólogas com um roteiro de entrevista semiestruturada com perguntas sobre (1) caracterização da atuação em Psicologia Escolar das participantes em OP; (2) percepção sobre os aspectos presentes no processo de escolha profissional no ensino médio; e (3) caracterização das atividades desenvolvidas pelas psicólogas na escola em OP.

Para a construção das informações e análise dos resultados, foi realizada uma análise de conteúdo dos dados obtidos nos questionários, que sondaram a percepção e atuação profissional das psicólogas entrevistadas, levando em consideração as seguintes etapas, segundo Bardin (2011): leitura de dados; estabelecimento de categorias e interpretação das informações.

Ao analisar as respostas colhidas dos questionários, verificou-se também os sentidos e significados dados pelos participantes, pois, conforme diz Vygotsky (2000, p. 465), “[...] o sentido é sempre uma formação dinâmica, fluida, complexa [...] O significado é apenas uma dessas zonas de sentido que a palavra adquire no contexto de algum discurso”. E, assim, foram 
construídas reflexões e discussões dos resultados em relação ao que fundamentou a pesquisa. O desenvolvimento do pensamento, da linguagem e da comunicação é fundamental para a complexidade das atividades superiores, sendo através do desenvolvimento da linguagem e da comunicação que se pode constituir o pensamento.

\section{Resultados e Discussão}

A descrição dos resultados foi delineada a partir da análise das respostas de três questionários semiabertos aplicados nas quatro psicólogas escolares de duas escolas privadas de São Luís - MA, citadas como Escola 1 (E1) e Escola 2 (E2). As psicólogas foram referenciadas como PA e PB da Escola 1 e PC e PD da Escola 2.

As categorizações temáticas construídas por meio dos discursos das participantes foram organizadas em categorias (Tabela 1, 2 e 3) e indicadores temáticos a partir das principais perguntas dos questionários. Cada indicador apresentado correspondeu às informações construídas nos resultados ao passo em que se descreviam e elucidavam questões do problema deste estudo.

\subsection{Dados de formação e tempo de serviço dos psicólogos escolares}

Na Tabela 1, apresenta-se a categorização temática com os dados colhidos, no primeiro questionário, a respeito da modalidade, níveis e abordagem de atuação das psicólogas escolares entrevistadas.

Tabela 1. Caracterização da atuação das psicólogas escolares.

\begin{tabular}{|c|c|c|c|c|}
\hline \multirow[t]{2}{*}{ Dados de atuação } & \multicolumn{4}{|c|}{ Participantes } \\
\hline & PAE1 & PBE1 & PCE2 & PDE2 \\
\hline Atuação como PE & 2 anos & 15 anos & 3 anos e 7 meses & 1 ano e 5 meses \\
\hline $\begin{array}{l}\text { Nível de Ensino } \\
\text { em que atua }\end{array}$ & $\begin{array}{l}\text { Ensino } \\
\text { Fundam } \\
\text { ental e } \\
\text { Médio }\end{array}$ & $\begin{array}{l}\text { Ensino Fundamental e } \\
\text { Médio }\end{array}$ & $\begin{array}{c}\text { Ensino Infantil, } \\
\text { Fundamental e Médio }\end{array}$ & $\begin{array}{l}\text { Ensino Infantil, } \\
\text { Fundamental e Médio }\end{array}$ \\
\hline $\begin{array}{c}\text { Modalidade de } \\
\text { Atuação na Escola }\end{array}$ & $\begin{array}{c}\text { OP; } \\
\text { Formaçã } \\
\text { o de } \\
\text { Professo } \\
\text { res }\end{array}$ & $\begin{array}{c}\text { OP; Formação de } \\
\text { Professores; Atendimento } \\
\text { clínico }\end{array}$ & $\begin{array}{l}\text { OP; Formação de } \\
\text { Professores; } \\
\text { Atendimento às } \\
\text { famílias, alunos e } \\
\text { funcionários; } \\
\text { Acompanhamento dos } \\
\text { ANEE. }\end{array}$ & $\begin{array}{l}\text { OP; Formação de } \\
\text { Professores; } \\
\text { Atendimento às } \\
\text { famílias, alunos e } \\
\text { funcionários; } \\
\text { Acompanhamento dos } \\
\text { ANEE. }\end{array}$ \\
\hline $\begin{array}{l}\text { Abordagem } \\
\text { Teórica do } \\
\text { Psicólogo }\end{array}$ & $\begin{array}{c}\text { A. } \\
\text { Centrada } \\
\text { na } \\
\text { Pessoa }\end{array}$ & Terapia Comportamental & $\begin{array}{c}\text { Formação em } \\
\text { Logoterapia e Análise } \\
\text { Existencial }\end{array}$ & $\begin{array}{c}\text { Análise do } \\
\text { Comportamento }\end{array}$ \\
\hline
\end{tabular}

Fonte: Autores (2021).

De acordo com a Tabela 1, pode-se perceber que todas as psicólogas escolares entrevistadas atuam nos Ensinos Fundamental e Médio, tanto na OP como na Formação de Professores. PBE1 já tem muitos anos de atuação como psicóloga escolar. Observou-se que duas seguem abordagens de base humanistas/existenciais e as outras duas são de áreas 
comportamentais, o que pode sugerir tendência a individualização das intervenções na escola e maior aproximação de modelos clínicos de atuação. O perfil do psicólogo escolar ainda restrito é um quadro característico da região maranhense, como discutido por Galvão e Marinho-Araujo (2018) e Galvão, Oliveira e Matos (2017), indicando uma limitação da formação inicial e continuada do psicólogo para perspectivas teóricas da Psicologia que se filiam a concepções e escolhas epistemológicas que consideram as origens históricas, sociais, políticas e culturais dos fenômenos que ocorrem na escola. Conforme destacam Carvalho e Marinho-Araujo (2010, p. 225), ao enfatizarem a relevância do psicólogo escolar atuar na perspectiva da Educação para Carreira, destacam que esse profissional "deve favorecer a implicação de toda a instituição educativa na realização de ações voltadas ao desenvolvimento da carreira dos alunos", alertando sobre a tendência de psicólogos atuarem na escola com base em um modelo clínico de intervenção em temáticas como OP.

\subsection{Percepção das psicólogas acerca dos aspectos que estão presentes no processo de escolha profissional do aluno do Ensino Médio.}

$\mathrm{Na}$ Tabela 2, mostra-se a categorização temática e, em seguida, suas análises, envolvendo os pontos principais observados, da segunda parte do questionário, acerca da percepção das entrevistadas sobre o processo de escolha profissional dos estudantes do Ensino Médio.

Tabela 2. Indicadores temáticos e respostas sobre adolescência, aspectos socioculturais e implicações da Reforma do Ensino Médio na Escolha Profissional.

\begin{tabular}{cc}
\hline Indicadores & Trechos das respostas dos participantes \\
temáticos &
\end{tabular}

\begin{tabular}{|c|c|}
\hline $\begin{array}{l}1-\mathrm{O} \text { jovem e a } \\
\text { busca de identidade }\end{array}$ & 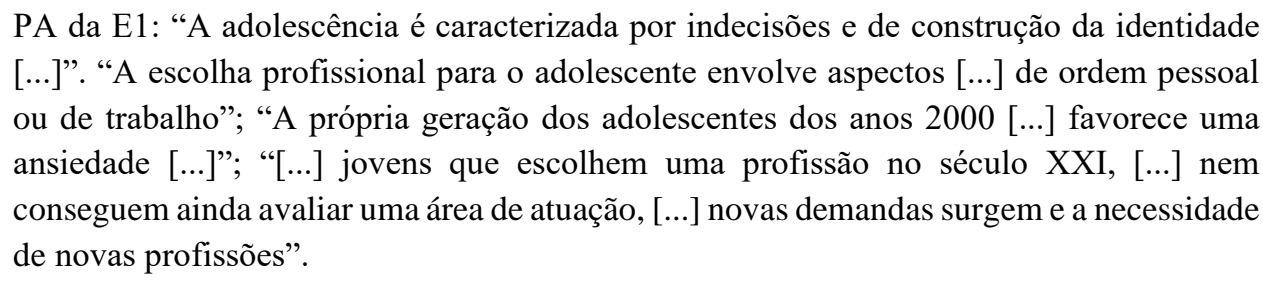 \\
\hline $\begin{array}{l}\text { durante o processo } \\
\text { de Escolha } \\
\text { Profissional }\end{array}$ & $\begin{array}{l}\text { PB da E1: "Ausência de autoconhecimento, falta de informação das profissões, mercado } \\
\text { de trabalho; visão limitada do que é sucesso, felicidade, realização profissional; falta de } \\
\text { compromisso das escolas em contribuir [...] processo". }\end{array}$ \\
\hline & $\begin{array}{l}\text { PC e PD da E2: "A suposta maturidade que todos os alunos já tenham atingindo, mas que } \\
\text { na verdade muitos não a possuem [...] percebe-se que a falta de autoconhecimento de saber } \\
\text { o que eu quero, como eu quero e o que devo fazer para atingir o meu objetivo [...] esses } \\
\text { jovens buscam no outro [...] respostas para não tomarem suas decisões sozinhos e no futuro } \\
\text { ter que se arrepender [...]vivem uma fase de reestruturação do "núcleo do eu", as estruturas } \\
\text { psíquicas/corporais, familiares e comunitárias sofrem mudanças conflitantes. Lutos e } \\
\text { fragilidades psíquicas afloram [...] tende a buscar autonomia, prazer e status, agindo de } \\
\text { maneira compulsiva e por vezes até agressiva". }\end{array}$ \\
\hline \multirow{2}{*}{$\begin{array}{l}\text { 2- Percepção de } \\
\text { aspectos protetivos } \\
\text { de pais e } \\
\text { professores sobre a } \\
\text { escolha profissional }\end{array}$} & $\begin{array}{l}\text { PA da E1: "As cobranças no aspecto familiar e social são constantes: 'ser bem-sucedido' } \\
{[\ldots] \text { além das pré-determinações dos padrões sociais de cada profissão". }}\end{array}$ \\
\hline & $\begin{array}{l}\text { PB da E1: "Influência de pais e professores, em especial, pois os querem muito bem, mas } \\
\text { possuem uma visão limitada e acreditam que com suas falas, sem propriedade, estão } \\
\text { contribuindo. Pensam que os alunos só serão felizes, só terão sucesso, em determinadas } \\
\text { profissões [...], a partir de pesquisas e vivências que é o profissional". }\end{array}$ \\
\hline
\end{tabular}


3- Percepção sobre a Reforma do Ensino Médio (MP) $746 / 16$.
PC e PD da E2: "[...] a influência da família [...] muitos jovens acreditam que devem seguir o exemplo dos pais que deram certo, ou, têm medo de se posicionar e decepcionar seus pais".

PA da E1: "Percebo que a reforma é um processo equivocado de modificação da metodologia de ensino [...] com a MP 746/16, o adolescente precisará definir antes mesmo da conclusão do Ensino Médio a escolha por uma área de preferência e se dedicar a ela. Caberá à escola saber como orientar essa decisão? Como o Ensino Fundamental II irá se estruturar para preparar esse adolescente para esta próxima etapa? Como ensinar um adolescente sobre questões tão profundas [...] até para os adultos são tão abstratos [...]". Concordo que os conteúdos do Ensino Médio são muito densos [..] Será que o governo não está olhando para o lado errado então?".

PB da E1: “[...] a escolha da área, não será um tanto penosa para o aluno, pois este já convive desde cedo com as áreas de conhecimento, consegue estabelecer bem suas afinidades e interesses. A escolha da área não significa a escolha da profissão e mesmo se o significasse, existem reescolhas. O Brasil é o país do mundo com maior quantidade de conteúdo no EM, esta reforma trará uma aprendizagem mais significativa para o aluno".

PC e PD da E2: "Com a possibilidade da oferta de autonomia aos alunos na escola quanto à sua escolha para a área de atuação profissional, compete às estruturas pedagógicas uma base curricular capaz de promover espaços para o estudo e orientações direcionadas ao mercado de trabalho, empregabilidade, [...] ao autoconhecimento e, assim, gerar maiores subsídios [...] quais possíveis perfis profissionais se identificam [...] será necessário que a escola intensifique os projetos e as ações relacionados com o processo de orientação ainda nos anos finais do ensino fundamental".

Fonte: Autores (2021).

Os resultados dessa categoria (Tabela 2), referentes ao indicador temático 1, apontam para as dificuldades e a busca de identidade com que o aluno se depara no Ensino Médio, que coincide com o período da adolescência, tendo que escolher uma profissão ou curso, algo que provoca nele muita ansiedade, tanto de ordem pessoal como relacionado ao mercado de trabalho, devido às constantes transformações sociais, características do século XXI, conforme a PA da E1 relatou no questionário. Já a PB da E1 e as PC e PD da E2 citaram a falta de autoconhecimento e de informações sobre as profissões como as principais dificuldades.

Concorda-se com as falas das participantes, principalmente no que se refere à importância do autoconhecimento, pois como que diz Fraiman (2014, p. 24), “Pode uma pessoa fazer boas escolhas sem, de fato, conhecer a si mesma?”. Nessa mesma visão, Neiva (2013, p. 22) enfatiza que "a informação profissional é de extrema importância dentro do processo de escolha. Entretanto, não é aconselhável fornecê-la antes que o adolescente tenha suficiente conhecimento sobre si mesmo".

Quanto ao indicador temático 2 sobre a influência dos pais e professores, compartilha-se da mesma concepção das psicólogas PA e PB da E1 e a das PC e PD da E2 que enfatizaram a mesma opinião a respeito de muitos adolescentes serem influenciados pelos pares, professores e, principalmente, pela família, passando a seguir escolhas pré-determinadas e, muitas vezes, até sob influência intensiva dos pais. Neiva (2013, p. 66) relata isso quando diz que "os valores familiares transmitidos ao adolescente também influenciam profundamente a decisão".

Perguntou-se também às participantes se já haviam acompanhado algum caso envolvendo a família dos adolescentes sobre escolha profissional e PA, PC e PD disseram que não, somente PB relatou que sim e acrescentou: "[...] a escolha profissional é do aluno, mas precisa ser produto de uma ação conjunta". Reafirma-se essa fala, por ser bastante pertinente e enfatiza-se a presença do psicólogo escolar nesse contexto, porque seria um mediador dos processos de desenvolvimento humano e educacional, ajudando docentes, gestores, alunos e seus familiares com estratégias de intervenção (Facci, 2014; Guzzo \& 
Marinho-Araujo, 2014).

Em relação ao indicador temático 3 sobre a Reforma do Ensino Médio (MP) 746/16, a PA da E1 destacou que se trata de um equívoco do governo, pois o jovem estaria sendo pressionado a escolher um curso antes mesmo de concluir o Ensino Médio. Entretanto, a PB da E1 já diverge desse pensamento, pois relata que o estudante teria condições de estabelecer seus interesses uma vez que desde cedo conviveu com as áreas de conhecimento e ainda ressaltou que a reforma traria um aprendizado mais significativo para o alunado, diferente do que se observa atualmente, nessa etapa, que conta com um aglomerado de conteúdos para os alunos, ponto esse que a PA da E1 também concordou.

As PC e PD da E2 relataram que para colocar em prática essa reforma, as escolas precisariam criar espaços, projetos e subsídios que viessem favorecer o processo de escolha profissional, iniciando logo nos últimos anos do Ensino Fundamental. A PA da E1 colocou como indagação se os ambientes escolares estarão preparados para auxiliar os alunos a respeito de questões tão complexas sobre a escolha de uma profissão/curso. Concorda-se com essa fala, porque, conforme a literatura utilizada, as escolas não estão bem estruturadas para receber tal reforma e que realmente há uma grande quantidade de assuntos sem base significativa para os alunos, tanto que os índices brasileiros quanto a uma boa qualidade na educação ainda continuam em posição bastante inferior em relação a muitos países (Melo-Silva et al., 2019).

\subsection{A atuação do psicólogo escolar no processo de Orientação Profissional (OP) de estudantes do Ensino Médio}

A seguir, na Tabela 3, são destacadas as atuações, em campo, das psicólogas escolares entrevistadas em relação às dificuldades encontradas em sua prática e os instrumentos que utilizam para o desenvolvimento de suas atividades.

Tabela 3. Indicadores temáticos e respostas sobre atividades, desafios e apoios que o psicólogo escolar encontra no processo de OP e o papel do professor na mediação da escolha profissional.

Indicadores Trechos das respostas dos participantes
temáticos

1- Tipos de

Atividades voltadas à $\mathrm{OP}$

2- Desafios do Psicólogo

Escolar na temática OP
PA da E1: "Atendimento individual aos alunos por livre demanda. O trabalho em grupo fica a cargo da disciplina Projeto de Vida".

PB da E1: "Leciono aulas semanais, com material didático específico para Orientação Profissional no EM".

PC e PD da E2: "Triagem sobre as principais áreas de interesse; Workshop das profissões; Palestras com profissionais da área; Atendimento com os alunos, quando solicitado [...]”.

PA da E1: "Na atual instituição, o trabalho nesta área é bem estruturado [...] no entanto, a principal dificuldade [...] não entendem este assunto como um processo e esperam soluções imediatas ("aplica um teste que tá bom"). [...] para discutir estes aspectos com as famílias necessitam do aval das instituições. O tempo na carga horária, o espaço para a realização de grupos ou atendimentos individuais que visem a este fim $[\ldots]$ ”.

PB da E1: “[...] temos a disciplina Projeto de Vida no Currículo desde o Fund. 2, o nosso desafio baseia-se mais em trabalhar o processo da escolha a cada ano de forma gradativa e no investimento com a família em compreender e participar do Projeto”.

PC e PD da E2: “[...] com o universo de 1.650 alunos, o nosso maior desafio é a gestão do tempo para realização de trabalhos contínuos [...] Além, da densidade do currículo do terceiro ano do ensino médio que dificulta a flexibilização de horários no mesmo turno [...]”.

3- Materiais PA da E1: “A escola tem a disciplina de Projeto de Vida, ministrada por psicólogas e começamos úteis ao a realizar grupos de estudo sobre o tema". 


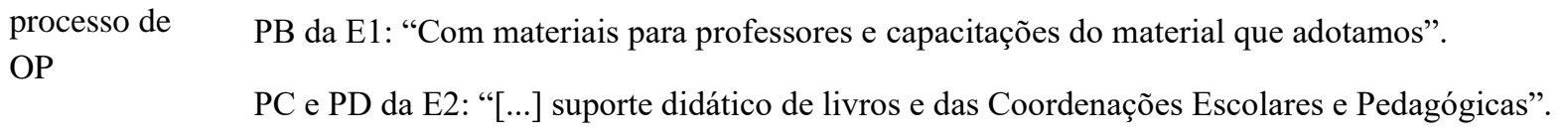

PA da E1: "[...] É também no contexto da sala de aula que as dúvidas e ideias surgem acerca das escolhas. Os docentes assumem um papel muito importante nesse processo, desde o não

4- Mediação docente no processo de escolha profissional direcionamento para determinadas profissões por serem mais 'aceitas' socialmente, até a consideração de que a escolha deve ser realizada de forma consciente, com as possibilidades de cada um".

PB da E1: "De orientador, como o parceiro com mais experiência e conhecimento do aluno, de fazê-lo encontrar respostas para os seus questionamentos [...] O professor é o articulador dos processos que envolvem as escolhas do aluno".

PC e PD da E2: “[...] é de extrema importância nesse processo, representa uma figura de referência [...], possibilitando várias possibilidades de atuação e aplicabilidade do conhecimento no mercado de trabalho, além de ser instrumento de motivação para os alunos".

Fonte: Autores (2021).

Nessa categoria (Tabela 3), os resultados referentes ao indicador temático 1 destacaram que todas as quatro psicólogas realizam atendimento com os alunos, quando solicitado. A PA e PB da E1 disseram que dão aulas semanais da disciplina Projeto de Vida com um material para OP no Ensino Médio que é o livro Construção do Projeto de Vida e Escolha Profissional e que também supervisionam as professoras que lecionam a mesma disciplina. As PC e PD da E2 mencionaram que fazem triagens, palestras e workshops sobre as profissões, porém não há OP na matriz curricular da instituição. Todas enfatizaram a importância da OP aos jovens do Ensino Médio. Concorda-se com Lisboa (2017) e Carvalho (2017) quando destacam que a OP é um instrumento fundamental para a criação de projetos profissionais, ajudando os estudantes no processo de inserção no mundo do trabalho, auxiliando-os na construção de sua emancipação psicossocial.

No indicador temático 2, foram citados os principais desafios encontrados pelo psicólogo escolar na visão das quatro entrevistadas. A PA da E1 e as PC e PD da E2 comentaram sobre o tempo, sendo um dos principais desafios para a realização de atividades contínuas e a PB da E1 citou que o seu desafio era trabalhar o processo da escolha a cada ano de forma gradativa e a participação da família no projeto da escola sobre o processo de OP. Souza (2014) comenta que o psicólogo, no âmbito escolar, pode abrir espaços para refletir acerca da diversidade de concepções sobre desenvolvimento humano no curso da vida, que inclui os processos relativos à escolha profissional dos estudantes. Nesse sentido, acrescenta-se que os desafios existem, porém, com abertura à reflexão os mesmos podem ser superados dada a possibilidade de circulação de novos sentidos sobre a visão que o adolescente, muitas vezes, atribui à transição do ensino médio para o ensino superior (Marinho-Araujo, 2016).

Quanto ao indicador 3, observou-se que as duas escolas visitadas contam com psicólogas escolares para desenvolverem um apoio aos estudantes sobre escolha profissional. E a escola 2 tem em sua base curricular a disciplina "Projeto de Vida", ministrada pelas psicólogas e que, recentemente, começaram a realizar grupos de estudo sobre o tema junto à equipe escolar. Observou-se que ambas as instituições se preocupam com as dificuldades dos estudantes no decorrer do processo de escolha de um curso/profissão e que o papel do psicólogo escolar, inserido na equipe pedagógica, é algo relevante para um melhor acompanhamento dos adolescentes nessa fase de busca de identidade, como também suporte aos seus familiares que fazem parte dessa etapa de escolhas e, por vezes, inseguranças (Carvalho, 2017; Carvalho \& Marinho-Araujo, 2010; Dias et al., 2019).

É importante ressaltar que o psicólogo escolar brasileiro, cada vez mais, tem se defrontado com espaços diferenciados de práticas pedagógicas, ampliando suas atuações (Martinez, 2010). Corroboram com essa visão Carvalho e Marinho-Araujo (2010), Martinez (2010), Soares e Krawulski (2010), Oliveira e Neiva (2013) e Guzzo e Marinho-Araujo (2014) quando 
salientam que as questões referentes à revisão e ampliação da atuação do psicólogo nos espaços educacionais não é algo novo, uma vez que já é visto como uma constatação para profissionais e pesquisadores que têm como foco a identidade do psicólogo escolar no país. E, nesse amplo leque de atuações, há o seu trabalho também voltado à OP.

No indicador 4, foi enfatizado o papel do professor como mediador no processo de escolha profissional e todas as psicólogas escolares tiveram a mesma concepção a respeito da importância do docente em relação à motivação de seus discentes, assim como o articulador de maior conhecimento dos estudantes. E, conforme Souza (2014), o psicólogo pode colaborar para a configuração de novos sentidos e significados, atuando como parceiro dos educadores na escola. Defende-se, portanto, um trabalho multiprofissional, em uma perspectiva colaborativa, onde o psicólogo escolar e o professor podem juntos contribuir com o desenvolvimento psicossocial não só dos alunos, mas de todos os que compõem o ambiente educacional, sobretudo fortalecendo o papel do professor nesse processo junto aos estudantes em seu cotidiano (Marinho-Araujo, 2016).

\section{Considerações Finais}

O objetivo dessa pesquisa foi a conhecer a percepção e a atuação de psicólogas escolares de duas escolas privadas de Ensino Médio de São Luís - MA sobre o processo de escolha profissional dos alunos e, por meio dos questionários aplicados, pôde-se concluir que as entrevistadas demonstram compromisso e empenho com os estudantes na fase de escolha de uma profissão, proporcionando-lhes apoio psicossocial, despertando-lhes senso de autonomia e responsabilidade consigo mesmos e com o meio à sua volta de forma crítica, participativa e consciente de seu papel como futuros mobilizadores sociais no mercado de trabalho e na sociedade como um todo. Os indicadores temáticos extraídos das respostas das participantes sugerem que os adolescentes do Ensino Médio necessitam de um acompanhamento psicológico no seu coletivo para desenvolver melhor seu autoconhecimento e ter mais condições de superar momentos de angústias e descobertas para fazer escolhas mais assertivas conforme o seu perfil e contexto social, significando e ressignificando suas decisões.

Percebeu-se, segundo a literatura e respostas analisadas das psicólogas escolares, que muitos fatores influenciam a escolha de uma profissão, como o autoconceito, busca de identidade, falta de informações, mercado de trabalho, novas demandas sociais e a família, uma das principais influenciadoras dos jovens nesse processo de decisão. Esta pesquisa apresentou algumas limitações, como a dificuldade de encontrar, nas escolas de São Luís, psicólogos escolares fazendo parte da equipe pedagógica (são raros os casos). Outro ponto foi a falta de tempo disponível desses profissionais para conseguirem responder aos questionários, por isso, foram respondidos pelo correio eletrônico.

A partir dos resultados e discussão deste estudo, que objetivou fornecer um levantamento mais detalhado e crítico da atuação do psicólogo escolar em OP, espera-se colaborar para que ações desenvolvidas nas escolas possam considerar os estudantes adquirirem novos conhecimentos sobre a teoria e a prática de uma profissão, a diversidade de carreiras, de cursos universitários e técnicos, de maneira crítica e reflexiva, ampliando seu processo de conscientização sobre a escolha profissional. Estima-se, portanto, que esse estudo possa trazer contribuições positivas para futuras pesquisas relacionadas às temáticas desenvolvidas no decorrer desse trabalho e sugere-se que outras sejam realizadas, abordando a contribuição do psicólogo escolar inserido numa equipe multiprofissional, em favorecimento da formação profissional dos alunos do Ensino Médio e, de preferência, começando essa prática no Ensino Fundamental.

Dessa forma, os dados constataram que é muito relevante a inclusão de OP como disciplina da educação formal nas escolas, não se restringindo apenas a ações esporádicas ou mesmo o encaminhamento para o acompanhamento clínico de fora da escola. Essa tendência de atuação do psicólogo escolar como parte integrante da instituição é importante para o desenvolvimento de projetos e ações coletivas com o corpo técnico-pedagógico direcionados à tomada de decisão, fortalecimento socioemocional e redução de conflitos pessoais oriundos das expectativas dos estudantes e seus familiares, tendo o psicólogo escolar como articulador e mediador do processo. A especificidade do trabalho desse profissional está voltada a aspectos 
comportamentais e de aprendizagem pela coletividade. Portanto, ao considerar a complexidade do percurso da escolha de uma profissão para o adolescente, defende-se que a OP é um campo de atuação indispensável para a Psicologia Escolar uma vez que a escola é o espaço privilegiado para o desenvolvimento humano.

\section{Referências}

Ambiel, R. A. M., Ferraz, A. S., Simões, N., Silva, J., \& Pereira, E. (2019). Predição da definição da escolha vocacional a partir de variáveis familiares. Avances en Psicología Latinoamericana, 37(1), 89-101.

Bardin, L. (2011). Análise de Conteúdo (L. Reto; A. Pinheiro, Trad.). Edições 70. (Trabalho original publicado em 1977).

Campos, R. R. F., \& Noronha, A. P. P. (2016). A relação entre indecisão profissional e otimismo disposicional em adolescentes. Temas em Psicologia, 24(1), 219-232.

Carvalho, F. C. S. (2017). Oficina “universo das profissões”: Um instrumento pedagógico na orientação profissional de alunos do ensino médio [Monografia não publicada]. Universidade Federal de Sergipe.

Carvalho, T. P., \& Marinho-Araujo, C. M. (2010). Psicologia escolar e orientação profissional: Fortalecendo as convergências. Revista Brasileira de Orientação Profissional, 11 (2), 219-228.

Dias, A. C. G., Carlotto, R. C., Oliveira, C. T. \& Teixeira, M. A. P. (2019). Dificuldades percebidas na transição para a universidade. Revista Brasileira de Orientação Profissional, 20 (1), 19-30.

Facci, M. G. D. (2014). No cotidiano da Escola: A adolescência desperdiçada? In R. S. L. Guzzo \& C. M. Marinho-Araujo (Eds.), Psicologia Escolar: desafios e bastidores na educação pública (pp. 111-133). Alínea.

Fraiman, L. (2014). Construção do Projeto de Vida e Escolha Profissional: metodologia OPEE: 2a série, Ensino Médio (4a ed.). Editora Esfera.

Galvão, P.; Carvalho, T. O.; Matos, D. C. (2017). Psicologia Escolar no Maranhão: História da formação e tendências atuais para atuação. Revista Psicologia: Ensino e Formação, 8 (1), 1-16.

Galvão, P; Marinho-Araujo, C. M. (2018) Psicologia Escolar e Políticas Públicas no Maranhão: História e compromissos atuais. In V.L.T Souza; F.S.B Aquino; R.S.L Guzzo \& C.M. Marinho-Araujo (Eds.), Psicologia Escolar Crítica: Atuações emancipatórias nas escolas públicas (pp.185-216). Alínea.

Grings, J. A., \& Jung, C. F. (2017). Fatores que influenciam na escolha profissional e a importância da orientação vocacional e ocupacional. Revista Espacios, $38(15), 12-31$.

Guzzo, R. S. L., \& Marinho-Araujo, C. M. (Eds.). (2014). Psicologia escolar: Desafios e bastidores na educação pública. Alínea.

Lehman, Y. P. (2010). Orientação Profissional na Pós-modernidade. In R. S. Levenfus \& D. H. P. Soares (Eds.), Orientação vocacional e profissional (2a ed., pp. 19-30). Artmed.

Leontiev, A. (1978). Sobre o desenvolvimento histórico da consciência. In A. Leontiev (Ed.), O desenvolvimento do psiquismo, pp. 89-142. Horizonte Universitário.

Levenfus, R. S. (Ed.). (2016). Orientação vocacional e de carreira em contextos clínicos e educativos. Artmed.

Lisboa, M. (2017). A formação de orientadores profissionais: um compromisso social multiplicador. In M. Lisboa \& D.H.P. Soares (Eds.), A orientação profissional em ação: Formação e prática de orientadores profissionais, pp. 19-38. Summus.

Marinho-Araujo, C. M. (2016). Perspectiva Histórico-Cultural do desenvolvimento humano: Fundamentos para atuação em Psicologia Escolar. In: C. M. Marinho-Araujo; M. V. M Dazzani \& V. L. T. Souza (Eds.). Psicologia Escolar Crítica: teoria e prática nos contextos educacionais. Alínea.

Martinez, A. M. (2010). O que pode fazer o psicólogo na escola? Em aberto, 23 (83), 39-56.

Meireles, J. \& Guzzo, R. S. L. (2020). Assembleias de classe: Psicologia Escolar na promoção da participação de estudantes. In: Marinho-Araujo, C. M.; Teixeira, A. M. B. (org.). Práticas exitosas em psicologia escolar crítica. Alínea, 2020.

Melo-Silva, L. L., Munhoz, I. M. S., \& Leal, M. S. (2019). Orientação profissional na educação básica como política pública no Brasil. Revista Brasileira de Orientação Profissional, 20 (1), 03-18.

Oliveira, C. M. R., \& Neiva, K. M. C. (2013). Orientação vocacional/Profissional: avaliação de um projeto piloto para estudantes da educação profissional. Revista Brasileira de Orientação Profissional, 14 (1), 133-143.

Sant'Ana, W.P., \& Lemos, G.C. (2018). Metodologia científica: a pesquisa qualitativa nas visões de Lüdke e André. Revista Eletrônica Científica Ensino Interdisciplinar, 4(12), 531-541.

Santos, D. C. O., Menezes, A. B., \& Costa, T. D. (2019). Avaliação da importância e aplicabilidade de competências de psicólogos escolares e educacionais. Revista de Psicologia da IMED, 11(1), 66-82.

Soares, D. H. P., \& Krawulski, E. (2010). Modalidades de trabalho e utilização de técnicas em orientação profissional. In R.S. Levenfus \& D.H.P. Soares (Eds.), Orientação vocacional e profissional ( $2^{\mathrm{a}} \mathrm{ed}$.) pp. 247-259. Artmed. 
Research, Society and Development, v. 10, n. 2, e16810212329, 2021

(CC BY 4.0) | ISSN 2525-3409 | DOI: http://dx.doi.org/10.33448/rsd-v10i2.12329

Souza, V. L. T. (2014). O psicólogo na escola e com a escola: a parceria como forma de atuação promotora de mudanças. In R. S. L. Guzzo \& C. M. MarinhoAraujo (Eds.), Psicologia Escolar: Desafios e bastidores na educação pública, pp. 27-54. Alínea.

Vygotsky, L. S. (1996). Obras escogidas IV: Psicologia infantil (incluye paidología del adolescente). Visor.

Vygotsky, L. S. (2000). A construção do pensamento e linguagem. Martins Fontes. 